\title{
Strong-Cation-Exchange Chromatography
}

National Cancer Institute

\section{Source}

National Cancer Institute. Strong-Cation-Exchange Chromatography. NCI Thesaurus. Code C161774.

A form of column chromatography where the stationary phase contains functional groups that are negatively charged. 